\title{
Mediating the Message of Action Research
}

\author{
Terry Sefton \\ University of Windsor \\ Sheila Windle \\ University of Windsor
}

\begin{abstract}
In this paper we argue that a multimedia composition of various data sources is an ideal and appropriate medium for conveying the contextspecific, teacher-directed, flexible and cyclical (non-linear) nature of collaborative action research (CAR). This compilation also expresses four main process outcomes of eight CAR studies in southwestern Ontario during 2007-2008: bridging the school-university gap, meaningful professional development, the "catch-22 of time," and complexity.
\end{abstract}

Almost a half-century since Marshall McLuhan (1964) first coined the phrase, "The medium is the message," his most quoted dictum continues to be routinely acknowledged and just as routinely ignored. While technologies of the $21^{\text {st }}$ century enable unprecedented levels of creativity and variety in presentation media, most scholars still "give papers" aurally, often alongside visual, textbased, projections. Though graphics and photographs appear more frequently through such programs as Power Point, users may remain unconscious to the reality that these programs come with their own sets of aesthetic and semiotic templates (Van Leeuwen, 2008) with conservative, predictable appearances and limited choices. It appears that by focusing almost exclusively on the central, obvious figure or "content" of the message, the "ground" or medium of the message is still often ignored (Federman, 2004; McLuhan). This being the case, researchers may be unknowingly limiting the "impact" of findings by limiting the medium of expression almost exclusively to text.

We propose that, while text-based presentations may effectively convey some academic ideas, for other messages, they are inadequate and perhaps even misrepresentative in their relatively simplistic, predictable, linear format. To elaborate the latter case, this paper relates the rationale behind choice of medium to communicate findings about the process of a collaborative action research (CAR) project undertaken by eight teams of teacher-researchers in Southwestern Ontario. By integrating conceptually our research findings and medium of presentation, we offer a format that explains our findings in a more holistic manner and comes closer to expressing the essence of our findings than could be affected through text-only presentation. Finally, we invite readers to experience our multimedia presentation online and then, if suitably provoked, to join in the 
discussion and/or practice of mediating academic presentations in the $21^{\text {st }}$ century.

\section{Method}

\section{Evolution of Multimediation}

The seed of our alternative mode of presentation was sown by the Call for Proposals to the Provoking Research proVoking Communities Conference, sent out by the Faculty of Education, University of Windsor. The call encouraged researchers to present collaboratively and in provocative formats; to "portray their work from multiple perspectives that apply new methods to meet the research needs of their communities" (Provoking, 2008). Author Sheila Windle responded to the call with a proposal for "8 Stanzas of Collaborative Action Research," in which eight stanzas of poetry, illustrated by photographs and accompanied by music, would convey the process of action research undertaken by eight teams of teacher-researchers in southwestern Ontario. In consultation with her research partner, a third colleague, Author Terry Sefton who is both professional musician and arts-based educator, was invited to accompany the presentation with live music.

Upon learning more about the research project and the data that had been collected, however, Sefton suggested something different than simply a musical accompaniment for the presentation. She offered to compose a "score" that would combine the various sources of data into a multimedia compilation - the resulting "music" would be layered voices or polyphony, created by both visual and aural means. The score she created (see Figure 1) displays various textual, audio and pictorial forms to be "played" or presented simultaneously. These elements - photographs of field trips, email correspondence with teacherresearchers, interview audio clips and reports, were compiled as a "movie" through a computer software package. A final performative component was to be added during the presentation, in which the researchers read aloud from their field notes while the movie simultaneously plays, thus both performing the role of researcher and enacting a live performance that includes the elements of chance, voice, temporality, and audience interaction.

As discussions of this multimedia presentation progressed, the two researchers became more enthused and convinced that the multimedia presentation would more truthfully reflect the content they were attempting to convey, for example, its iterative, simultaneous rendering of multi-layered data (medium) would more accurately portray the action research process (message), all of which resonated with McLuhan's idea, "the medium is the message." It should be clarified, however, that McLuhan's message itself was not quite so straightforward. He was not simply suggesting that the medium is the message, and that the more obvious content was irrelevant. Rather, he was encouraging people in the technological age "to look beyond the obvious and seek the nonobvious changes or effects that are enabled, enhanced, accelerated or extended" by the new medium (Federman, 2004, p. 2). As McLuhan stated, "societies have always been shaped more by the nature of the media by which men [sic] communicate than by the content of the communication" $(1967$, p. 8). He used 
the sentence as a prime example, wherein the phonetic English alphabet is strung together uniformly across the page, massaging our senses in a step-by-step, linear process that shapes our habit of thinking in bits and parts, thereby fostering a fragmenting process, a process of specialism and detachment. Electric technology, on the other hand, in McLuhan's view, was more apt to foster unification and involvement; and it was the medium that ultimately created lasting sociological effects.

Within the present research, we felt it was important to heed this suggestion because the predictable, text-based, linear format of a traditional conference presentation - that is, the medium - needed to be recognized as being a part of the message and if it that be true, then it — as well as the formal content - needed to be considered and critiqued. Our presentation format, therefore, could be considered a counter-narrative to the more common research presentation narrative that generally follows the predictable storyline of Introduction, Theoretical Base, Method, Results and Conclusions. In fact, our findings suggested a very different model: that action research was a cyclical, back-andforth, reflective, multi-layered process with the added complexity of contextspecificity and urgency. As such, we were intentional in aligning our medium with the message, with the aim of re-presenting more truthfully and authentically the process of action research as experienced and described by participants. In order to visually and conceptually unify the numerous data sources, Terry Sefton created a score (Figure 1), which she will explain in the following section.

\section{Medium}

Some explanation of the score and how it functions compared to conventional text would be appropriate at this point. Textual practices within academic journal writing are, as noted above, well established; and academic readers of such texts are well practiced in navigating meaning according to the norms of their particular disciplines and discourses. In the world of performing musicians, the musical score is a comparable textual device with some important differences. The score is a replicable text, that can be read by any trained musician, and that provides a guide for performance. A musician can reproduce the intentions of the composer years, even centuries, after the score has been created.

The difference between a conventional text and a score is the difference between reading and performing. Whereas a textual document can be published and disseminated in hard copy or electronically and reproduced exactly in different locations with no variation, a score, by convention and intention, is a vehicle for performance; and performance is ontologically unstable. One theory of semiotics contends that text is not stable, and that each reading of a text produces a unique and constructed meaning, activated by the reader; others hold that text is stable, and that the reader may project meaning onto or extract meaning from a text; but the text itself is immutable. A score, while appearing to be stable, provides a guide for performance: performance is time contingent and therefore transient, ephemeral; and each performance produces a unique interpretation, as co-created or realized by the performer. It is possible to record a performance and thereby document and preserve a particular performance; but it is not possible to replicate a live performance. 
8 STANZAS OF COLLABORATIVE ACTION RESEARCH

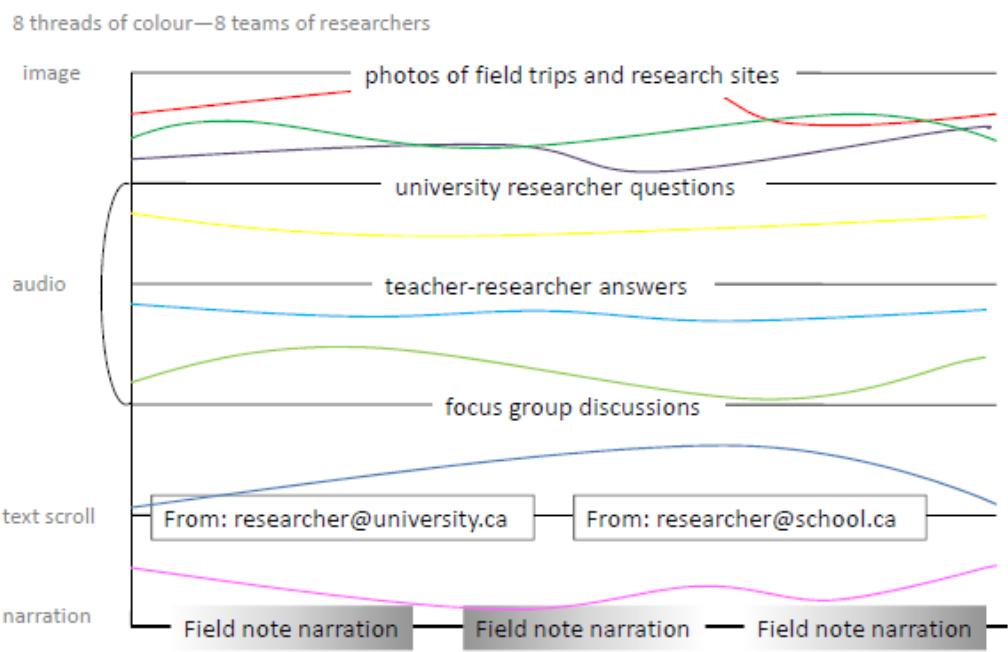

Figure 1: Score

This score was developed from the elements of this particular research project. In a musical score, each line (or staff) usually signifies a voice or musical instrument, but in the present research project, each line represents a single data source. Since there are six different data sources (i.e., photographs of field trips; audio clips of teachers' responses/dialogue; audio clips of interview questions; audio clips of interview mediation; email text scroll from and to teacher researchers and university researchers; and live narration of researcher field notes), six lines are stacked one above the other, running horizontally and parallel to each other. At any given moment, between one and six different sounds or events will be happening simultaneously. When reading the score from left to right, it is possible to see that simultaneity by looking at all six lines, one above the other. Individually, each voice follows a linear (horizontal) path. Collectively (vertically), all voices create a polyphonic whole, greater than its parts, as voices interact, layer, reverberate, conflict, or reinforce each other. This arts-based medium, in its capacity to represent the surfeit of data sources, matches the message of the multi-layered complexity of classroom life in which yet another layer, action research, took place. Finally, the eight coloured strands weaving through the score do not represent data, but symbolically represent the eight research teams. Any researcher could adapt this score to organize and present her or his research.

The university researcher/authors took a risk in stepping outside traditional textual methods of writing and presenting. After presenting-performing this work for the Provoking Research proVoking Communities conference, the authors revised the video, revised the text, transformed and refined photo and audio resources, and re-presented at the American Educational Research Association 
the following year. As with other time-based art, each performance is a unique event, and each encounter will produce a new reading. The creative process of revision, the experience of performing on a different stage to a different audience, and the validation that comes from the enthusiastic response from an audience of their peers, confirmed a sense of the significance and appropriateness of mediating the message of Action Research. As well, according to Federman, the whole idea is that "we can know the nature and characteristics of anything we conceive or create (medium) by virtue of the changes - often unnoticed and nonobvious changes - that they effect (message)" (2004, p. 2).

The next section presents findings one by one, and in doing so, contradicts to some degree the points already made. However, if the reader keeps in mind the visual musical score, it is easier to conceptualize that all of these findings occur simultaneously rather than singly, in a neat line, as the textual medium might subliminally suggest. First, we address three characteristics of action research that teacher researchers identified as enablers of the CAR process: (a) flexible and cyclical, (b) context specific, and (c) teacher-directed and empowering. After explaining how each theme manifests in the present study, we explain how the multimedia presentation parallels and portrays these principles. Next, we explicate four themes emerging from the teacher researchers' responses to questions about the CAR process: bridging the school-university gap, meaningful professional development, the "catch-22" of time, and complexity. Again, with each theme, we explain how these findings (message) are embedded and reflected in the medium. Parallels between this arts-based medium of presentation and the characteristics of Collaborative Action Research (CAR) suggest a strong potential for innovative collaborations between researchers in CAR and Arts Based Educational Research (ABER).

\section{Findings}

\section{Flexible and Cyclical (Non-linear)}

While action research is "systematic inquiry by teachers with the goal of improving their teaching practices" (Rock \& Levin, 2002, p. 7), the process is intentionally flexible in order to allow changes in, for example, data collection and recording procedures, necessitated by the natural fluidity of classroom life. What we call flexibility, Goodnough (2008, p. 452) terms the inherent "messiness and uncertainty" of action research. These essential characteristics, according to Goodnough, are necessary as teacher-researchers grapple with new ideas and construct shared meanings. The first two comments epitomize the flexible aspect of the CAR process and the final four convey its continuous, cyclical nature.

Donna: ... but we didn't get to the last strategy because our plan did change so having flexibility was essential, because our schedules are always changing.

Marlene: We were going through the whole process together, so when things weren't happening the way we'd hoped, we came back and talked about them and together came up with solutions so we were 
modifying and improving as we went along and that's what reflective teaching is.

Reinforcing teacher-researchers' descriptions of back-and-forth changes to original research plans during the present school year, and plans for changes the following year, our presentation was decidedly cyclical in its iteration of photographs and audio clips. Photographs were randomly placed to parallel spontaneity and flexibility; repeated images approximated the "to-and-froing" (Brown \& Jones, 2001, p. 9) of reflective action research. It is not surprising, given the nature of action research, that most models depict recurring cycles of observing, acting and reflecting (e.g., Lewin's Action Research Spiral, 1951; Riel's Action Research Model, 2007; Stringer's Action Research Interacting Spiral, 2007), and this ongoing aspect of Action Research is clearly communicated in the next interview excerpts.

Bonnie: So, now that we've done this, next year we will be better able to judge what to do more and less of.

Katherine: I keep hearing us asking more questions - it's that series of questions that just keep driving deeper and broader investigations.

Abigail: this time I read it much more closely and because I know what problems we had and what obstacles we came up against, so different things jumped out at me and I thought, I wish I had noticed this in September but ... I wasn't there yet so it took us back.

Colleen: So next year, from the beginning of the year, as a full class, every Friday, I will ...

Katherine's comment about questions "driving deeper and broader investigations" resonates with Hannay's (1998) description of the Action Research process: "as one turn of the spiral is complete, other questions emerge" (p. 40). This cycle unfolds naturally in the educational setting as teachers make plans for the following school year based on this year's findings. Because of this cyclical nature of action research, we chose the wind turbine (see Figure 2) to be the symbol of our investigations into CAR; it appears repeatedly throughout the video.

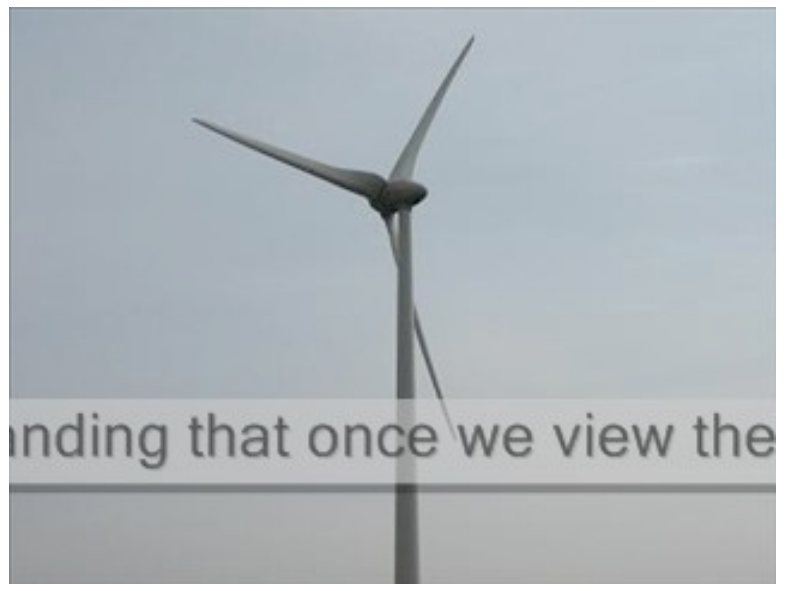

Figure 2: Wind turbine: flexible, cyclical, nonlinear 
The image of the wind turbine, captured along the Bluewater Highway en route to a site visit to Kincardine, Ontario, also represents the next aspect of action research, its context-specific nature.

\section{Context-specific}

Any description of action research identifies the specific context as an essential part of this approach (Bogdan \& Biklen, 2003; Corey, 1953; Goodnough, 2008; Johnson, 2008; Mills, 2003; Sagor, 1992, 2005). Sagor emphasizes that Action Research "is conducted by people who want to do something to improve their own situation" (p. 7). Similarly, "Action research allows teachers to study their own classrooms ... in order to better understand them and be able to improve their own quality or effectiveness" (Mertler, 2009, p. 2), as the interview data confirm.

Karinna: So, with our specific group of kids, we needed to spend more time creating schema.

Stacy: I think when it comes down to it this was really all about us changing our own instruction and the changes we saw in the children because of us changing our practice...

Donna: I find that interferes with the ESL students' comprehension because they may not have an understanding of things that we take for granted.

Karinna: The time to actually go through some of that literature ... and working out how they [strategies] would work with our specific community of kids.

Theresa: And it made you think more about what books you were using and why.

These extracts reflect Mertler's ideas exactly, i.e., the context-specific nature of CAR enabled teachers to study their particular classrooms and their particular students more closely and as a result, their teaching and their students' learning improved. In an attempt to translate some of the nuances of context into our findings, we incorporated numerous photographs of the research sites and the teacher-researcher teams (Figures 3 and 4). While it would have been richer to photograph students as well, we did not have this liberty due to ethical restrictions. The photographs became the video track of the "movie," allowing the audience to gain a sense, visually, of the eight distinct research contexts. Direct access to teachers' voices through digital soundtrack also provides contextual cues through tone, tempo and stress of utterances. Within the context of their own schools, their own classrooms, and occasionally their own homes, the teacher researchers described this CAR opportunity as empowering because it was teacher-directed, as elaborated in the next section. 


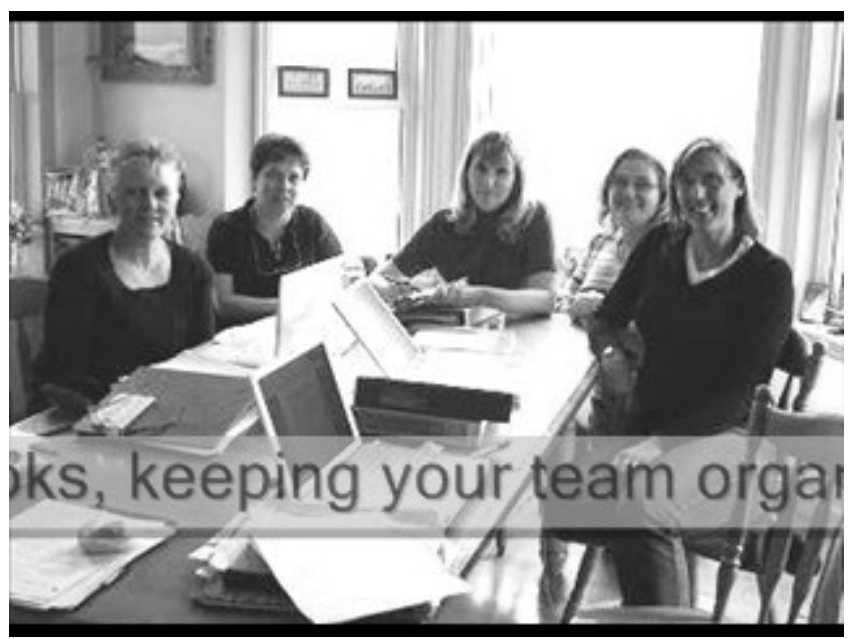

Figure 3: Research team "at home"

\section{Teacher-directed and Empowering}

CAR should be "teacher-directed rather than principal-imposed" as one of the teacher-researchers stated. "Furthermore, action research affirms the professionalism of teaching by giving teachers a real voice in their own professional development, as opposed to being told by someone else" (Mertler, 2009 , p. 22). In the present study, these expectations of action research were realized:

Wanda: I think this is a very powerful model because the teachers like, we - have ownership of it.

Katherine: I do think the action research can't be something that's forced upon teachers or it loses the essential power of what it is.

Stacy: It's got to be driven by the needs the teachers are seeing in the classroom.

Having ownership meant the teacher researchers determined the topic of investigation based on the needs they saw in the classroom; they chose the methodology; they chose the data sources and the scheduling of data collection. The teams were also self-selected, which lent itself to group accountability and seeing the study through to completion. Finally, the teacher researchers were responsible for writing their research report, which was a practical way of giving voice to their research process and findings.

In aligning our own research presentation with the teacher-directed nature of action research (Churcher, 2007; Hannay, 1998; Mertler, 2009; Mills, 2003; Sagor, 1992, 2005; Stringer, 2007), it was important for us to centralize the voices of the teachers in this project. As such, teachers' voices, images, and text messages dominate the multimedia composition. Their voices literally reach the audience; their verbatim email messages run across the bottom of the screen; their faces, schools, homes, towns, cities and roads make up the video. While we, as university researchers, still exercised control in choosing the focus group questions, the audio excerpts to highlight, the photos to include (in what order, for how long, etc.), we did our best to represent the teachers' emic perspectives 
which came from extraordinarily rich and complex analytic frameworks (Cochran-Smyth \& Lytle, 1993, p. 58). Mutual respect between teacher researchers and university researchers in this project may have played a part in bridging the school-university gap that often exists.

\section{Bridging the School-university Gap}

One of the main arguments in support of action research in Corey's seminal educational text, "Action research to improve school practices" (1953) was bridging the unnecessary divide between university researchers and classroom teachers. Since then, numerous studies have identified Action Research as one effective means of bridging this gap (Bogdan \& Biklen, 2003; Churcher, 2007; Conway \& Jeffers, 2004; Watkins, 2006). Interview data suggest this was also an outcome of the present CAR project.

Donna: Having you [university partners] coming and helping guide us along the way was helpful because I've never done this so having that meeting back earlier in the year and laying it out helped me learn about doing action research.

Mary: being paired with you two [university partners] because we are immersed in the practice aspect of teaching whereas when you came, you brought the research piece and always answered our questions and it kept us on track.

Bonnie: You've given us some guidance - big time guidance.

Karinna: You [university partners] brought the research and theoretical pieces and we brought the practical application.

We believe an approach of mindfulness and respect (Bentz \& Shapiro, 1998; Smith, 1999) on the part of teachers and university researchers contributed to a narrowing of the gap between researcher and researched (Cochran-Smyth \& Lytle, 1993). Our medium of presentation likewise dissolves the division between expert presenter and less informed audience. The role of the viewer shifts from academic audience to performance art spectator, and with that move, added challenges and possibilities are implied: to interpret, to witness, to participate in the co-creation of meaning in a visual and cultural field (Becker, 1996; Foster, 1996; Preusse, 1999).

When used as a site for research, art practice brings into play the seamless relationship between the 'researcher' (artist) and the 'researched' (art practice) and this builds on all the discursive arguments that disrupt untenable dichotomies such as the fictive subjective-objective divide. (Sullivan, 2006, p. 31)

As such, this format parallels the shift facilitated through action research wherein teachers are no longer cast only as spectators or consumers of "other people's research"; they become active creators of and contributors to the professional knowledge base (Cochran-Smith \& Lytle, 1993; McRae \& Parsons, 2007; Sagor, 1992, 2005; Shank, 2002; Watkins, 2006). Along these lines, meaningful professional development was another major finding. 


\title{
Meaningful Professional Development
}

One of the most commonly cited benefits of CAR is meaningful professional development (Blumenreich \& Falk, 2006; Churcher, 2007; Conway \& Jeffers, 2004; Goodnough, 2008; McRae \& Parsons, 2003; Mills, 2003; Noffke \& Stevenson, 1995; Sagor, 2005; Watkins, 2006). The present study was no exception as professional development (PD) took various forms: collaboration in lesson planning, the sharing of educational resources; time to read from the research literature; and the opportunity to work with university researchers.

\begin{abstract}
Colleen: For me, the opportunity to get together with colleagues on a regular basis and just be ... totally focused. I have just so much enjoyed - that professional development for me personally and how collegial the group has been. It has just been a fantastic year; just fantastic.

Theresa: I really enjoyed the collaboration. I liked the process, how we decided we were going to tackle it, how we were going to address each one of the strategies and then I liked the collaboration on the sharing of the ideas and making up of the lessons and looking at our work to see if we were on the right track or if we saw differences between our kids. I got a lot out of that professionally.

Bonnie: Well even sitting here today, and going over what we all did during the year, and what we found good and bad and ugly ... you know, it's really nice to have that open-ended conversation like that.

Stacy: I think this is by far the most powerful PD I've ever done.

Wanda: And I definitely prefer it as PD compared to what we normally have. I really prefer it.
\end{abstract}

The last two excerpts contrast this PD with traditional formats, organized by administrators for teachers' passive consumption (Mertler, 2009), which they often found irrelevant and/or useless to their own practice. Linking this theme to the arts-based presentation of findings, the university-researcher/authors also experienced PD in moving beyond traditional presentation formats, and extending their knowledge of CAR and ABER, as well as their technical skills in multimedia. The original experience and learning produced by the research project was increased, enhanced, and transformed by the creative work involved in producing a video and performance. Working in a liminal zone, between scholarly discourse and musical performance, between stable text and time-based art, the film/performance speaks from, through, and to, the researcher, as participant, as observer, as knowledge producer and cultural consumer/user or "produser" (Bruns, 2009). Like the teacher researchers conducting CAR as an additional form of meaningful professional development, incorporating ABER as meaningful professional development, and the immense time commitment involved, the authors also experienced "the catch 22 of time." 


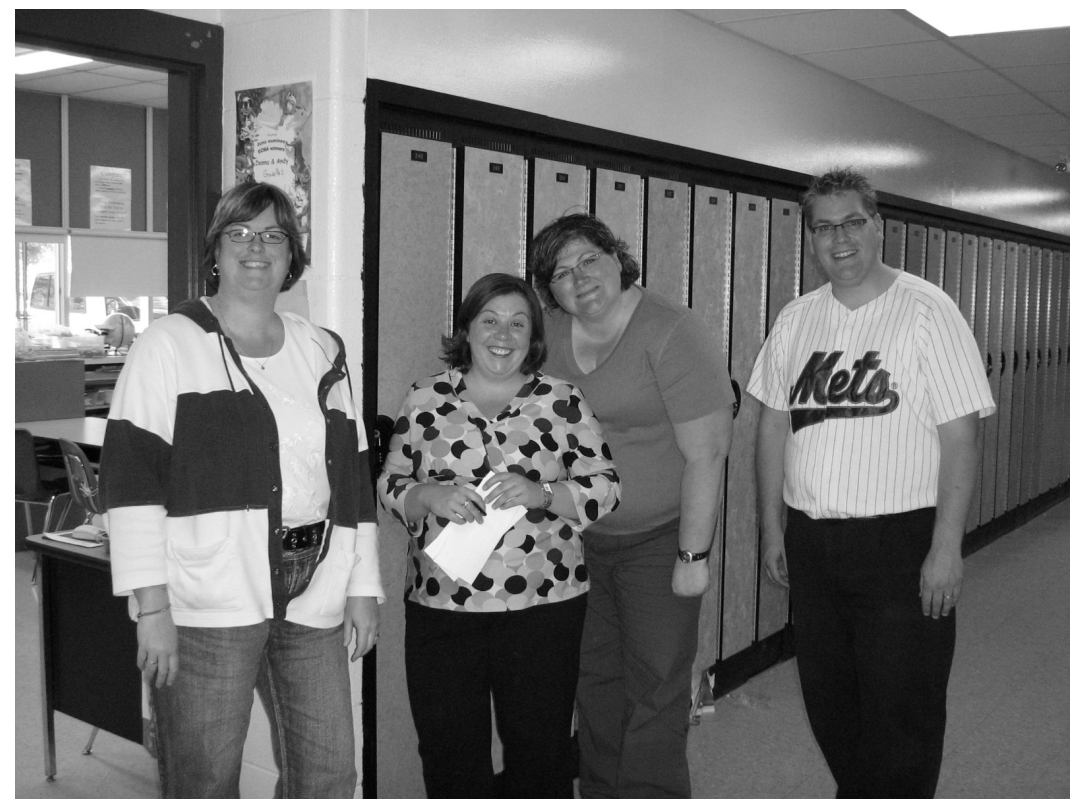

Figure 4: "I probably would have quit this year if it hadn't been for this group"

\section{The "Catch 22" of Time}

As in other CAR studies (Goodnough, 2008; Kuriloff et al., 2009; Watkins, 2006), the teacher researchers identified time as the number one challenge. While they had been given release time to plan and disseminate, there simply was not enough of it. Yet, more release time would have then meant less classroom time with their students, which would also have been unsatisfactory. One participant described this situation as "the catch- 22 of time." The theme of time is evident on the audio track and in the following quotations.

Abigail: It's been stressful trying to fit it all in and get everything done but I have learned a lot that I will continue to use with my students so ....

Theresa: We also felt that having large blocks of time to work together as professionals was invaluable.

Katherine: There was always this feeling of galloping for me and I never felt like I was doing enough of the professional reading because of the school year being what it is with the time, resources and energy.

Donna: It's probably like a catch 22, right? It's wonderful to have the time to get together and discuss and work on it, but then that's time taken away from you doing stuff in the classroom ....

The desire to "fit things in" and the feeling of "galloping," convey time pressure and urgency. The theme of time is one that the multimedia production communicated particularly well in that the images, sounds, and email text are presented briefly so that it is difficult and sometimes frustrating to take it all in. Though one may want to spend more time on a particular stimulus, there simply is not enough time, in the same way that teachers have limited time in the classroom. The medium, with its display of brief images reinforces the sense of 
urgency within the space-time continuum/illusion of film (Denzin \& Lincoln, 2003, p. 7).

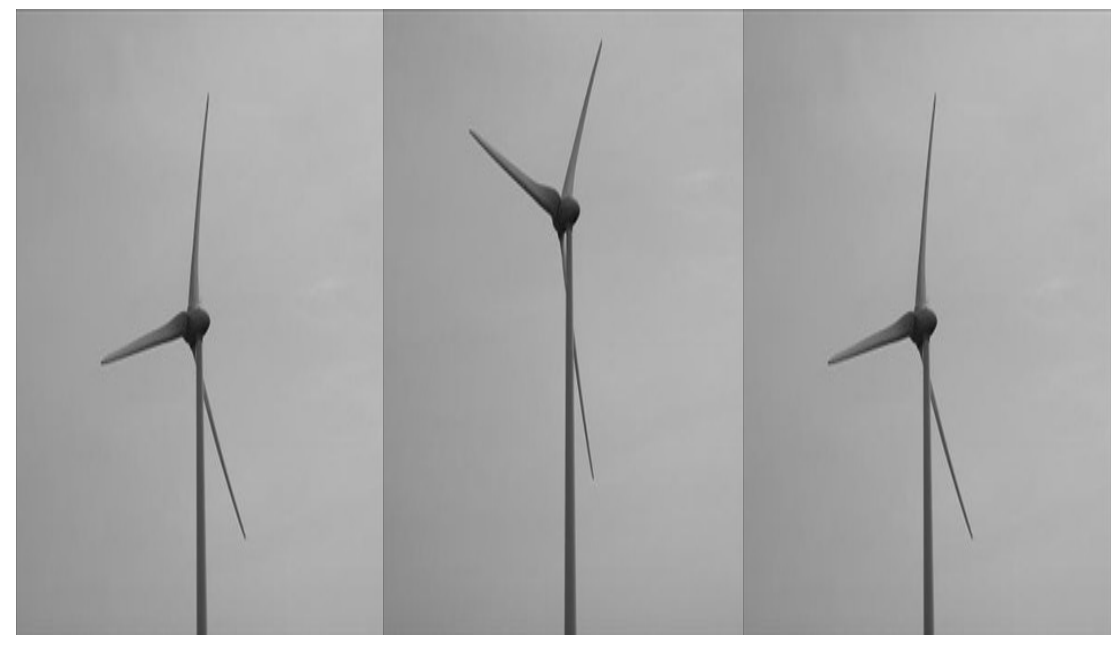

Figure 5: Space-time illusion

\section{Complexity}

In supporting and facilitating eight CAR teams, and analyzing data that explained their experiences of that process, complexity was a recurring theme. Sagor (2005) identifies complexity as a rationale for teachers as action researchers:

When the work is complex, when it requires an understanding of nuance and idiosyncratic behavior and calls for constant assessment by a trained eye as well as continual adjustments in the operative theories of action, it must be informed by the insights of those taking the action: the practitioners themselves. (p. 50)

Focus group comments reflecting complexity in teaching while carrying out the action research are as follows:

Abigail: If this is what you could focus on for three-quarters of the day that would be great but with the DRAs and the CASIs and the PLCs you feel a little frazzled some days.

In this excerpt, Abigail uses a number of abbreviations that are a standard part of the educational jargon, e.g., the Developmental Reading Assessment (DRA) for K-3 students; the Comprehension Attitude Strategies Interests (CASI), which diagnoses Grade $4-8$ students' strengths and needs related to Ontario reading expectations and achievement charts; and professional learning communities (PLCs), which continue to function as a professional development opportunity during the action research period. All of these pieces amid innumerable other factors in the complex teaching landscape lead to Anne feeling "frazzled" some days. Theresa's comments, next, convey the commitment required to get "great results" and reveal her motivation to putting in "a lot of work." 
Theresa: It's like a snowball because ... it seems like a lot of work and it is a lot of work but you feel like you're getting great results so, okay, I'm going to spend another Sunday choosing my books and planning the lessons because it's worth it ... but it is a lot of work, and a lot of focused work to make it meaningful and effective for the students.

Abigail's and Theresa's words illustrate in the educational realm what one of the pioneers of Action Research, John Collier, had predicted in 1945, i.e., that this kind of research, which makes severe demands on the researcher, requires "a more advanced and many sided training, and in addition a type of mind and personality which can sustain, in suspension, complex wholes" (p. 300). The next comment supports Collier's belief that conducting Action Research makes "severe demands."

Marlene: It's always an add-on so I don't think it's ever really easy. I think it's extremely necessary and important but I wouldn't say that there's ever a time when it's really easy.

Jane: This action research was so powerful because we could remove ourselves from our various roles as teachers and dive right into this in a separate space so the release days were essential, I thought.

The action research represented an additional layer to their already complex roles as teachers. It is not surprising, then, that a number of teacher-researchers reported feeling overwhelmed when it was time for data analysis and reporting. To collect, organize, analyze and construct meaning from a volume of data, all within a single school year, was a daunting undertaking. In order to represent this process, then, a simple and straightforward linear arrangement with clear, easily identifiable sections, though comfortable and even comforting, would be misrepresentative in its simplistic, orderly presentation. Even the use of dense words to convey complexity word by word, point by point, in a neat power point presentation would likewise be unsatisfactory if the findings were condensed into an unrepresentative "lineal order" (McLuhan, 1962, p. 178). Time did not stand still, nor were teachers' responsibilities put on hold. Everything occurred simultaneously; the experiences and the research process were not linear and orderly but in fact, "messy" (Goodnough, 2008).

Similarly, in analyzing our case study data, we were faced with a complex, multi-layered collection of data: email correspondence, team reports, photographs of field trips, audio clips of focus groups, and researcher notes. Bearing in mind that our mode of presentation also created an effect of its own and was thus an important part of the message, we decided that a polyphonic layering of data would more truthfully and powerfully convey the message of CAR's complexity within the school setting. The simultaneous rendering of photos with text and audio, sometimes overlapping photo images to create yet more layered montage (Figure 6), was intended to inundate the senses and disrupt the comfort of an academic audience, thus challenging and enabling them to experience allusively the complexity of conducting action research in an already complex work setting. Multiple modes of media appearing at one time put the audience in the position of having to actively select and make sense of numerous stimuli in a limited amount of time, just as the teacher-researchers had had to do 
with the data. In these many ways, the medium embellished the original report, which was focused on describing the process of CAR.

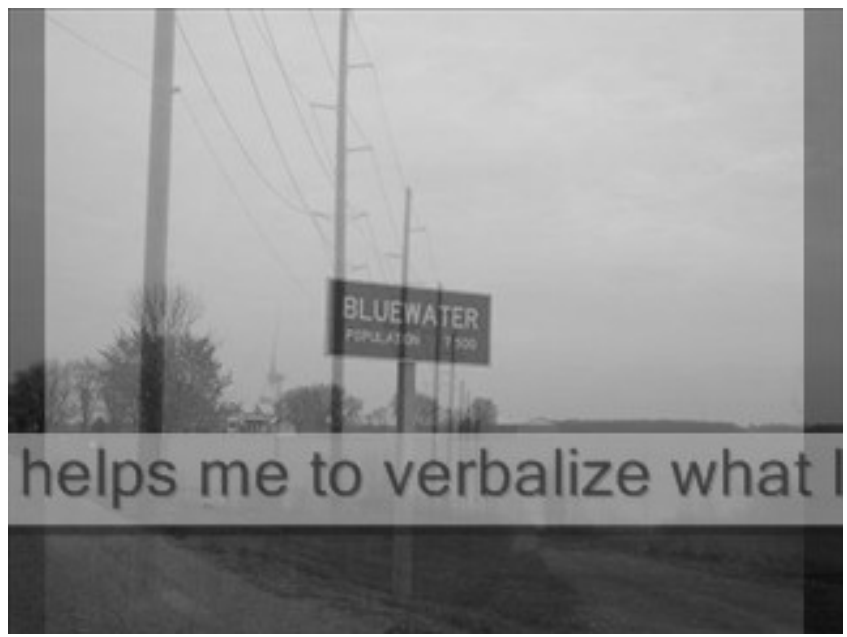

Figure 6: Photo montage layered with email messages

\section{Conclusion}

The irony of this paper is that, in order to reach our audience, we have expressed our message about a non-textual, non-linear medium of presentation through a traditional, textual, linear medium. While the photographs offer insights into the ideas and context of our research, overall we consider this a compromise between a misleading simplistic linearity and a holistic, unified, multi-layered complexity. We believe intuitively that there is untapped potential in matching medium with message, but as yet have limited experience in realizing the impact of presenting research in this way. We have seen the enthusiastic response of academics to our work; but ideally, action research belongs to the teacher/researcher participants and to the school communities that host the research projects. University partners are not the research 'experts' in this paradigm, but work to develop new strategies for inquiry and knowledge production that may (should) take them outside their comfort zone. This is bricolage, working with the tools at hand as well as using one's imagination to see and think differently.

An important next step would be to engage the teacher/researchers in this creative and multimodal way of working. Working collaboratively, with flexibility, over time, school and university partners take risks and develop new tools - within the lived complexities of educational communities. Though playful and artful, what we are suggesting is not easy. Rather, "the pursuit of such complex understandings is a lifetime pursuit, not something that one can learn merely in a short span of time" (Kincheloe, 2008, p. 134).

\section{References}

Becker, C. (1996). Zones of contention: Essays on art, institutions, gender, and anxiety. Albany, NY: State University of New York Press.

Bentz, V. M., \& Shapiro, J. J. (1998). Mindful inquiry in social research. Thousand Oaks, CA: Sage. 
Blumenreich, M., \& Falk, B. (2006). Trying on a new pair of shoes: Urban-teacher-learners conduct research and construct knowledge in their own classrooms. Teaching and Teacher Education, 22, $864-873$.

Bogdan, R. C., \& Biklen, S. K. (2003). Qualitative research for education: An introduction to theories and methods ( $4^{\text {th }}$ ed.). New York: Allyn and Bacon.

Brown, T., \& Jones, L. (2001). Action research and postmodernism: Congruence and critique. Philadelphia, PA: Open University Press.

Bruns, A. (2009). Blogs, Wikipedia, second life, and beyond: From production to produsage. New York: Peter Lang.

Churcher, K. (2007). From the bottom up: Researching n the classroom. Education Canada, 47(3), 64-66.

Cochrane-Smith, M., \& Lytle, S. L. (1993). Inside/outside teacher research and knowledge. New York: Teachers College Press.

Conway, C., \& Jeffers, T. (2004). The teacher as researcher in beginning instrumental music. Update: Applications of Research in Music Education (Online), 22(2), 35-45.

Corey, S. M. (1953). Action research to improve school practices. New York: Teachers College Press.

Denzin, N. K., \& Lincoln, Y. S. (Eds.). (2003). Collecting and interpreting qualitative materials (2nd ed.). Thousand Oaks, CA: Sage.

Federman, M. (2004). What is the meaning of the medium is the message? Retrieved June 10, 2010, from http://individual.utoronto.ca/markfederman/MeaningTheMediumistheMessage.pdf

Foster, H. (1996). The return of the real. Cambridge, MA: Massachusetts Institute of Technology.

Goodnough, K. (2008). Dealing with messiness and uncertainty in practitioner research: The nature of participatory action research. Canadian Journal of Education, 31, 431-458.

Hannay, L. (1998). Action research in everyday practice. Orbit, 29(3), 40-43.

Johnson, A. P. (2008). A short guide to action research (3rd ed.). Boston: Pearson Education.

Kincheloe, J. (2008). Critical pedagogy. New York: Peter Lang.

Kuriloff, P., Reichert, M., Stoudt, B., \& Ravitch, S. (2009). Building research collaboratives among schools and universities: Lessons from the field. Mind, Brain, and Education, 3(1), 34-44.

Lewin, K. (1951). Field theory in social science: Selected theoretical papers. New York: Harper.

McLuhan, M. (1964). Understanding media. New York: McGraw Hill.

McLuhan, M. (1967). The medium is the massage. Toronto: Bantam Books.

McRae, P., \& Parsons, J. (2007). Teachers as researchers: (Re)Searching within Alberta's schools. The ATA Magazine, Spring 2007, 14-17.

Mertler, C. A. (2009). Action research: Teachers as researchers in the classroom (2 ${ }^{\text {nd }}$ ed.). Thousand Oaks, CA: Sage.

Mills, G. E. (2003). Action research: A guide for the teacher researcher ( $3^{\text {rd }}$ ed.). Upper Saddle River, NJ: Pearson Education.

Moghaddan, A. (2007). Action research: A spiral inquiry for valid and useful knowledge. Alberta Journal of Educational Research, 53(2), 228-239.

Noffke, S. E., \& Stevenson, R. B. (Eds.). (1995). Educational action research: Becoming practically critical. New York: Teachers College Press.

Preusse, K. (Ed.). (1999). Accidental audience: Urban interventions by artists. Toronto: Offlsite.

Provoking Research proVoking Communities. (2008). Retrieved July 16, 2009 from http://web4.uwindsor.ca/prvc

Riel, M. (2007). Understanding Action Research. Center for Collaborative Action Research, Pepperdine Univerity. Retrieved August 26, 2009, from http://cadres.pepperdine.edu/ccar/define.html

Rock, R. C., \& Levin, B. B. (2002). Collaborative action research projects: Enhancing preservice teacher development in professional development schools. Teacher Education Quarterly, 29(1), 7-21.

Sagor, R. (1992). How to conduct collaborative action research. Alexandria, VA: Association for Supervision and Curriculum Development. 
Sagor, R. (2005). The action research guidebook. Thousand Oaks, CA: Corwin Press.

Shank, G. D. (2002). Qualitative research: A personal skills approach. Upper Saddle River, NJ: Merrill Prentice Hall.

Smith, L. T. (1999). Decolonizing methodologies: Research and indigenous peoples. New York: Zed Books.

Sullivan, G. (2006). Research acts in art practice. Studies in Art Education, 48(1), 19-35.

Stringer, E. T. (2007). Action research. Thousand Oaks, CA: Sage.

Van Leeuwen, T. (2008). New forms of writing, new visual competencies. Visual Studies, 23, 130135.

Watkins, A. (2006). So what exactly do teacher-researchers think about doing research? Support for Learning, 21(1), 12-18.

Dr. Terry Sefton teaches music education and research methods in the Faculty of Education, University of Windsor. Her research field is the sociology of art with a focus on the identity formation of artists and musicians and on higher education in the arts. She is a professional cellist, performing in orchestras and as a chamber musician, and often works with contemporary composers in developing and performing new works.

Dr. Sheila Windle teaches English as an Additional Language, Communication Across Cultures, Educational Foundations (Issues in Education), and Health and Physical Education Methodology. Her research interests lie in the areas of: cultural aspects of additional language acquisition and teaching; integrating cultural diversity into the high school physical education curriculum; and collaborative action research as a vehicle for professional development.

\section{ACKNOWLEDGMENT}

We acknowledge the valuable contributions of the participating teacher-researchers, the ETFO members who designed the Teachers Learning Together action research initiative, and the Ontario Ministry of Education, who funded this research. 